University of Wollongong

Research Online

Faculty of Business - Papers (Archive)

Faculty of Business and Law

2013

The reception of Anglo leadership styles in a transforming society: the case of American companies in Vietnam

Anne Vo

University of Wollongong, avo@uow.edu.au

Zeenobiyah N. Hannif

University of Technology, Sydney, zeenie@uow.edu.au

Follow this and additional works at: https://ro.uow.edu.au/buspapers

Part of the Business Commons

Research Online is the open access institutional repository for the University of Wollongong. For further information contact the UOW Library: research-pubs@uow.edu.au 


\title{
The reception of Anglo leadership styles in a transforming society: the case of American companies in Vietnam
}

\begin{abstract}
This article examines the transfer of Anglo leadership styles in a transforming society. It aims to investigate the transferability of two American leadership styles, namely performance-oriented and participative styles, to Vietnamese subsidiaries. Utilising an exploratory case study approach, this article presents evidence of a strong acceptance of these leadership styles, and tries to ascertain whether the adoption of a humane style of leadership in line with Vietnamese traditions is a means of leaders reconciling the cultural gap. Several complexities arise from the transforming nature of the Vietnamese socio-political and economic context. Specifically, the importance of subcultures - particularly those relating to generation - is highlighted. Situational contingencies, such as the skills set of the recipient group, also emerge as important considerations. Finally, the authors call for leadership dynamism as a means of facilitating congruence and adaptability between the leadership styles used and the various contextual complexities encountered in the transfer and reception process.
\end{abstract}

\section{Keywords}

era2015

Disciplines

Business

\section{Publication Details}

Vo, A. \& Hannif, Z. N. (2013). The reception of Anglo leadership styles in a transforming society: the case of American companies in Vietnam. International Journal of Human Resource Management, 24 (18), 3534-3551. 
The Reception of Anglo Leadership Styles in a Transforming Society: The Case of American Companies in Vietnam

Dr Anne Vo*

School of Management and Marketing

University of Wollongong

Northfields Ave, Wollongong, NSW 2522 Australia

Email: avo@uow.edu.au

Phone: +61242213973

Dr. Zeenobiyah Hannif

School of Management

University of Technology, Sydney, NSW 2007, Australia

Email: Zeenie.Hannif@uts.edu.au

Phone: +61 295143659 


\begin{abstract}
This paper examines the transfer of Anglo leadership styles in a transforming society. It aims to investigate the transferability of two American leadership styles, namely performance-oriented style and participative style, to Vietnamese subsidiaries. Utilising an exploratory case study approach, this paper presents evidence of a strong acceptance of these leadership styles, and tries to ascertain whether the adoption of a humane style of leadership in line with Vietnamese traditions is a means of leaders reconciling the cultural gap. Several complexities arise from the transforming nature of the Vietnamese socio-political and economic context. Specifically, the importance of subcultures — particularly those relating to generation — are highlighted. Situational contingencies, such as the skills set of the recipient group, also emerge as important considerations. Finally, the authors call for leadership dynamism as a means of facilitating congruence and adaptability between the leadership styles used and the various contextual complexities encountered in the transfer and reception process.
\end{abstract}




\section{Introduction}

Since the 1980s world economic development has entered a new and exciting era. Greater trade liberalisation, economic integration and regionalisation have become realities (Hirst \& Thompson, 1999). Concurrent with these economic developments has been the increasing challenge of managing a global workforce. The success of multinational firms (MNCs) depends critically on their ability to manage a global workforce, members of which are located not only in their home country, but also in various host countries (Dowling \& Welch, 2004). Several prominent researchers have proposed the notion of cross-cultural diversity in the realm of leadership (including Haire et al., 1966; Hofstede, 1976; 1980; Gonzalez, 2008). Many commentators accept that leadership behaviours are common across cultures, but cultural contingencies at both the national and organisational level deserve further scholarly attention (Ashkanasy, 2007; Dorfman et al., 2004; House et al., 1999), for example:

\footnotetext{
...the attributes and entities that distinguish a given culture from other cultures are predictive of the practices of organisations of that culture, and predictive of leader attributes and behaviours that are most frequently enacted, acceptable, and effective in that culture (House et al., 1999: 188).
}

Since the 1960s, research on cross-cultural leadership has been rich in quality and abundant in quantity. Although research on leadership on MNCs has made important steps forward, inadequacies remain. First, many leadership theories and practices are based on Western concepts and assumptions about human behaviours (House \& Aditya, 1997). Some authors question the transferability of such models to other business environments, arguing that an understanding of context (such as history, culture, political environment, and even workforce age and skill levels) are essential, because they influence attitudes and behaviours (see for example, Jackson \& Bak, 1998; Nevis, 1983); while others question the applicability of a leadership style 
developed in a Western context when applied to an Eastern setting (Huang et al., 2006; Tsui et al., 2004; Peng and Tjosvold, 2008).

Second, research into leadership style is considered a stem of cultural study often characterised by stability and slow transformation. Hofstede (1997) claims that culture is 'difficult to change'. However, observations of transforming economies, such as Vietnam or China, point out that within a space of a decade, major economic shocks can and have happened in these societies, and these have brought about significant changes in the societies and their cultures. Gamble (2001) examines the transferability of the British flat hierarchical structure into Chinese society, and argues that culture should be considered 'not as a static monolith but a shifting and changeable repertoire with diverse strands'. Leadership styles should be perceived in the same way — as adaptable and subject to change - a view not yet explored in the current stream of research.

Third, the extant research in this field neglects the transfer of leadership styles at the receiving end. Little, if any, research exists that examines the reception of leadership styles, particularly how are leadership styles received and adapted in new cultural settings to reflect the host country's cultural and societal context.

In view of these shortcomings in the literature, this paper addresses the transfer and reception of Anglo leadership styles in a transforming society. It investigates the transferability of two American leadership styles, namely: performance-oriented style and participative style, to Vietnamese subsidiaries. In particular, it aims to discover: 1) how the two leadership styles are transferred to Vietnam; 2) how organisations mediate and adapt to the local environment; 3) the reception of leadership styles by older and younger generations of Vietnamese employees. 
The paper is structured as follows. First, the literature review overviews the extant research on the transfer of leadership styles, as well as Vietnam as the host country for the transfer of leadership styles. Second, the research methodology is outlined. Third, the empirical study consists of three subsections: the transfer of participative- and performance-oriented leadership styles, the adaptation of leadership styles and the difference in the reception of leadership styles of older and younger generations. Finally, we offer some brief conclusions.

\section{Literature review}

\section{The transfer of leadership styles}

The notion of 'culture' is widely identified as an essential consideration in the examination of leadership concepts across diverse geographical contexts. Several researchers (for example, Adler, 1983; Feldman, 1986; Roberts \& Boyacigiller, 1984) focus on the development of a precise construct of culture, and establishing clear scientific methods to inform studies on the management of people and organisations across cultures. In particular, the work of Geert Hofstede (1980)'s Cultures Consequence introduced a typology of national culture, fundamentally challenging the application of ethnocentric management theories. He proposes four value dimensions (individualism, masculinity, power distance and uncertainty avoidance), which vary across cultures. A fifth dimension (long-term orientation) was later added to the framework.

More recently, the Global Leadership and Organizational Behavior Effectiveness Research Program (GLOBE) has established itself as the most comprehensive empirical assessment of leader attributes across different cultures (Muczyk et al., 2008). The GLOBE study establishes nine cultural dimensions (power distance, 
uncertainty avoidance, in-group collectivism, institutional collectivism, gender egalitarianism, assertiveness, humane orientation, performance orientation and future orientation) to illustrate differences and similarities in the values, beliefs and practices evident in different country clusters regarding the notion of leadership. The study identifies 65 leadership traits, which it then captured in six leadership styles, namely: performance-oriented style, team-oriented style, participative style, humane style, autonomous style and self-protective styles. The study found that while several attributes were universally seen as contributing to outstanding leadership, others were culturally contingent.

Of the six leadership styles identified by the GLOBE study, the participative leadership and performance-oriented leadership styles better characterised Anglo societies. The study describes the participative style as encouraging input from others in decision making and implementation and emphasising delegation and equality. The participative approach ensures diverse points of view are voiced, a feature which fosters and facilitates motivation, collaboration and cooperation (Khandwalla, 1995). Researchers have conceptualised participative leadership as a component of transformational leadership, and found it to have more relevance in individualised, Western societies (Bass, 1997). Gerstner and Day (1994) and Offermann and Hellmann (1997) suggest that effective leadership within collectivist societies tends to be more closely aligned with transactional and autocratic styles of leadership than transformational and participative styles. However, research by Tung and Avolio (1999) shows that collectivist societies that function under a transformational leader who uses a participative style are more likely to generate a wider range of ideas than those in individualistic societies. Similarly, the GLOBE study highlights the participative leadership style as being most valued in the Anglo, Nordic European and 
Germanic European regions, but less valued in Eastern Europe, most of Asia and the Middle East regions.

In the GLOBE study, performance oriented leadership is referred to as the charismatic/value-based approach, and also as a leadership style that focuses on the establishment of high standards, decisiveness on the part of the leader and innovation. Within this context, the leader is seen as seeking to inspire people around a shared vision or goal, who entices passion amongst follower to perform. They achieve this by holding on to the core values of the organisation. According to the GLOBE study, Anglo nations sit highest on measures of performance orientation; and while South East Asian countries also value this leadership characteristic, their placement relative to that of Anglo societies is less intense.

The success of the transfer of leadership styles to a host country depends several factors: the culture of the host country, the perception and reception of the leadership styles within the host country context, and the adaptability of the styles to the host country's culture. Hofstede (1980a) notes that leadership in any culture is ultimately a complement to 'subordinate-ship', and the feasibility of leadership styles greatly depends on the cultural conditioning of the subordinate group. In the situation of an expatriate manager, these pre-existing culturally legitimatised prototypes can influence the reactions of others to a non-native foreign manager in a way that may impede cross-cultural leadership success. As Brodbeck et al. (2000) argue, the perceptions of the host country audience (subordinates, colleagues, superiors) about the manager ultimately determine whether the foreign manager is considered 'leader' material. These perceptions influence whether that person's leadership traits and behaviours are accepted, and the degree to which the foreign leader is thereby perceived and deemed to be 'successful' in their role. The organisational reality of 
such a scenario means that the greater the disparity between the leadership concepts of foreign managers and the relevant attributers in a host country, the lower the likelihood of effective cross-cultural leadership (Ayman and Korabik; 2010; Den Hartog et al., 1999).

The adaptability of a foreign manager to the foreign cultural context is another key determinant of success. Some researchers support the notion of leaders as 'flexible', and thus capable of adjusting and adapting their leadership styles in line with the particular culture where they operate (Muczyk et al., 2008). However, most theories in the area of leadership were developed in North America, and embody a primarily ethnocentric point of view (Chin, 2010; Hofstede, 1983). Similarly, leaders emerging from the North American business context have developed leadership traits and characteristics within a cultural context that establishes, reconfirms and reproduces this ethnocentric frame of reference. Successful adaptability on the part of the leader requires the elimination of this ethnocentrism — or at least a reduced imposition of one's frame of reference on others, and a re-examination of the belief that one's cultural values are the same as everyone else's (Ayman and Korabik, 2010). In other words, foreign managers who maintain ethnocentric leadership schemata and exhibit ethnocentric leadership characteristics are more likely to behave in ways deemed inappropriate within the host country, and are less likely to be successful (Brodbeck, 2000).

Leadership effectiveness has been examined in a wide range of countries, but the Vietnamese context remains particularly under-researched (Ralston et al., 1999). The recent GLOBE study, for instance, includes both the South East Asian region (represented by the Philippines, Indonesia, Malaysia, India, Thailand and Iran) and Confucian regions (represented by Singapore, Hong Kong, Taiwan, China, South 
Korea and Japan) as clusters, but does not include Vietnam. Some similarities may exist between Vietnam and its neighbours which the study examined, but further research should not assume that notions of leadership that arise from the South East Asian region will necessarily be true of the Vietnamese context.

Quang et al. (1998) highlight key differences between the leadership characteristics that are valued in Vietnam compared to other ASEAN nations. Economic and social transformations that have occurred within Vietnam over the last 20 years add further interest to the Vietnamese business context as a subject of analysis. These developments are outlined further below in discussions of Vietnam as the context of leadership transfer.

\section{Vietnam as the host country for the transfer of leadership styles}

Vietnam's cultural heritage is deeply rooted, having developed over 4,000 years with strong Confucius influences (Quang, 2002). Confucians prioritise collective units such as the group, family and community over self-interest. They focus on order and hierarchy within the sphere of both family units and society. Senior members exercise authority over and expect submission and unquestioning obedience from the younger members. Confucius advocates a paternalistic regime in which the ruler is compassionate and honourable and his subordinates are respectful and obedient. According to the framework developed by Hofstede (1980), previous research on Vietnamese national culture describes it as having a high level of power distance, high collectivism, moderate uncertainty avoidance and high context (Quang, 1997, 2002; Ralston et al., 1999).

High power distance is reflected in family life, with children expected to have high levels of obedience to the heads of the family; and within organisations, where 
subordinate-superior relationships are clearly defined (Quang, 2002). Collectivism is another defining feature of the Vietnamese culture, where the role of the individual is recognised as being secondary to the group (Xingzong, 2000). Formal guidelines and tight social frameworks inform social interaction as a means of protecting a group's ‘face’ or reputation (Quang, 1997). The Vietnamese will generally avoid conflict; however, where it does arise, they strive for a win-win situation (Quang, 2002). Quang (2002) also suggests the Vietnamese culture is characterised by moderate levels of uncertainty avoidance. Ambiguity is largely regarded as a threat in the work environment, and is reconciled with greater job stability, the establishment of formal rules, and the rejection of deviant ideas and behaviours.

Having manifested over several centuries, these beliefs are deeply entrenched in the Vietnamese value system and heavily influence how firms are managed in Vietnam. Respect for authority, hierarchical order, collectiveness, consensus, cooperation and long-term commitment characterise the traditional Vietnamese firm. Nevertheless, Vietnam is a country that has undergone significant transformation over the past two decades, particularly since Doi Moi (economic reform) came into effect. In 1986 the Communist government ended its previous approach of maintaining a closed and centrally-planned economy and sought industrialisation by allowing private ownership of economic enterprises, encouraging a greater role for market forces and embracing an open-door policy towards foreign investment (Tran, 1997). These macro-economic developments also transformed the management of human resources in Vietnam, which is most obvious in foreign-invested companies (Vo, 2009).

Researchers and practitioners have been sceptical about the applicability of Western human resource management (HRM) practices in the Vietnamese context (for example, Tran, 1997; Vo, 2009). The examination by Quang and Vuong (2002) of the 
relationship between management styles and organisational effectiveness in three enterprise sectors (state-owned, privately owned and joint ventures) reveals that many Vietnamese managers still display authoritarian and familial styles of management, particularly in the state sector, and that this reflects the tradition of a centrally controlled system. The use of clear reporting relationships, formal communication and strict control reminiscent of a familial type of leadership are consistent with the Vietnamese culture; however, these practices may inhibit the competitiveness of larger, more complex corporations that operate in more turbulent environments. During the transitional period, there is a high level of interest amongst younger generations of managers to adapt more participative styles of management. This is a legacy of the expatriate managers who had brought with them modern principles of management to the joint venture operations.

Leadership within the context of Vietnam is also explored by Quang et al. (1998), and their research establishes a profile of compatible and complementary leadership characteristics, skills and behaviours for successful joint-venture relationships. Their research shows mixed results in terms of the compatibility of leadership styles between international managers (from the US, Europe and Asia) and Vietnamese managers. Similarities existed in the leadership of the two cohorts, particularly in terms of the emphasis on teamwork, people orientation, productivity, competitiveness, strategic vision, adaptability to the environment and long-term orientation. However, Vietnamese managers placed less value on collaboration-related behaviours, such as sharing power and delegation, and placed more value on control than performance.

While these studies provide important insight into the key differences between the leadership behaviours and practices of Vietnamese and expatriate leaders, little understanding exists about how Anglo leadership behaviours and styles are received 
in organisations that operate within this transforming society. While the literature confirms differences in leadership traits in different societal contexts, Vietnam has not been included in such studies. Little is also understood about the strategies used by MNCs to mediate and negotiate through differences in perception about what is regarded as effective leadership and the processes needed to adapt leadership behaviours. This paper addresses these gaps by examining the transfer and reception of Anglo leadership styles in Vietnam.

\section{Methodology}

Taylor et al. (1996) assert that cultural distance is the most important constraint on 'context generalisability' of HRM practices. To highlight the contrasts between the West and East, we chose MNCs originating in the US operating in Vietnam as the object of research. The largely exploratory nature of the research, and the need to examine in detail the leadership styles of the companies, meant that the case study approach was the most appropriate strategy (Yin, 2003). Case study research utilising qualitative methods provides a sophisticated instrument to capture the often subtle, complex, and changing ways in which leadership operates. Although a quantitative method is very useful for achieving a broad overview of patterns, it cannot capture successfully the complexity of the phenomenon and explain the differences in behaviour patterns.

This study is based on a multi-case design. We conducted interviews at five US companies operating in the automotive, fast-moving consumer goods (FMCG), and energy industries. We coded the investigated companies as follows: Auto Co, FMCG Co1, FMCG Co2, FMCG Co3 and EN Co. The study took place during a three-year period from 2008 to 2011. Within this time, two fieldwork trips were conducted in 
Vietnam and follow-up phone interviews were carried out afterwards. Multiple interviews were held with key informants to compile information on HRM policies and practices in general, and leadership styles in particular, with two groups of interviewees: managers and employees. In total, we carried out 57 one-to-one interviews, and also held nine focus group discussions comprised of five or six employees (See table 1). Three types of focus groups were arranged: all pre-1975 born employees, all post-1975 born employees and mixed groups. The average interview, both one-to-one and focus group, took more than one hour. The interviews included the following key themes: organisational history and structure; perception of leadership styles used in the company; the reception of participative and performanceoriented leadership styles; difficulties experienced and the adaptation of these leadership styles to local stituations; and generational effects in the perception and reception of these leadership styles.

\section{Insert Table 1 here}

While limited, the interviews conducted in situ allowed observation of the work environment and personal relationships within the firms. The purpose of observation was to validate and check stated versus actual leadership practices within each organisation, as well as to quality check the statements on wellbeing, job satisfaction and so on, of employees. The combination of data-gathering methods (that is, triangulation) is vital in the case study method for cross-checking data, thus ensuring reliability (Yin, 1994; Kelly, 1999). When a consistent picture emerged, through cross-checking interviewees' viewpoints, documentary analysis (when possible) and non-participant observation, collected information can be considered reliable. 


\section{Empirical findings}

The empirical findings are presented in three main sub-sections: the transfer of participative and performance-oriented leadership styles, the adaptation of leadership styles, and the difference in the reception of leadership styles of older and younger generations.

\section{The transfer of participative and performance-oriented leadership styles}

It emerged from the fieldwork data that within the studied US MNCs, participative and performance-oriented leadership were strongly present at managerial levels. EN Co defined their leadership style as transformational leadership, which emphasises inspiring, influencing, challenging and engaging. FMCG Co1 stressed a culture and working environment that 'challenges people from day one'. The company created early responsibilities for every employee and nurtured a culture where open communication processes were common and innovative ideas were proposed, critiqued, and refined with a minimum of social risk. The company also focused on creating a practice of open innovation to take advantage of the skills and interests of people throughout the company. Auto Co's leadership model included the principal of empowering people and utilising energy of grassroots leadership. The company's production manager said:

\footnotetext{
We want people at all levels adopt a 'can-do' attitude, make decisions and take calculated risks. In our production lines, the techniques and processes used to achieve these outcomes are as important as the results or outcomes. We cannot afford to wait for production and product innovation ideas to come down from the top.

Similarly, FMCG Co2 demanded their employees 'own your project'. FMCG Co3 developed six leadership qualities to help empower employees. Of these six qualities, effective collaborative behaviours required managers to actively seek the support and advice of team members and others outside the work group to assist in decision
} 
making and planning, build networks and collaborate with diverse groups. This also encouraged a diversity of opinions, and a culture of responding positively to ideas from others, both within and outside their own team.

In a sharp contrast with Vietnamese state-owned enterprises (SOEs), in the studied MNCs, employees' scope of work (and together, their responsibilities), had expanded vertically. Staff member had the opportunity to own a project - they would be accountable for and involved in every step of the process. This would demand collaboration at different levels inside the company and required them to be in touch with external customers, service providers and stakeholders. Employees at lower levels could report directly to the company directors in certain projects. Thus they not only had a sense of authority about what they did and how they did it, but also achieved job satisfaction when they saw their project finalised. This delegation and high level of autonomy reduced employees' sense of powerlessness, strengthened their belief in their own effectiveness and self-efficacy, and motivated them to discover new opportunities and encourage innovation (Arnold et al., 2000; Ahearne et al., 2005; Leach et al., 2003).

One important element of performance-oriented leadership style is to generate high performance standards by linking individual performance to the core values of the firms. Four out of five studied companies reported that they used the balanced scorecard as a strategic management tool, and that the objectives and measures of the scorecard were derived from the organisation's vision and strategy. Individual scorecards view organisational performance from different perspectives, such as finance, market share, cost, customer satisfaction, internal business process, growth and so on. For example, the balanced scorecard of Auto Co is built on a regional/global perspective, and includes five key business priorities: volume revenue 
and market share, cost and business structures, product program and execution, quality and customer satisfaction, and people and safety. Each department then develops their own business plan, which is linked to the company's balanced score. Individuals and teams in departments throughout the company then translate the higher-level strategic objectives into personal and team objectives.

In order to clarify as much as possible individual objectives and responsibilities these three US firms use SMART objectives. SMART objectives are set to be Stretch and Specific (objectives should be challenging and state exactly what will be achieved); Measurable (objectives must be quantifiable so that performance can be checked); Aligned (there must be a clear link between the objective and the business Balanced Scorecard); Realistic (while objectives should be challenging they should also be achievable); Time-Target (objectives should specify a completion data and milestones). Even though FMCG Co3 does not use Balanced Scorecard and SMART objectives, there is an extensive use of measurable objectives. In essence, there is one principle controlling individual objective setting in the studied US companies: achieving clarification in the individual objectives and ultimately pushing up individual performance.

Performance-oriented leadership style was reinforced in the investigated companies by the use of forced distribution in performance rating (see Table 2). It was more popular amongst the white-collar group of employees (especially top management and management) than for blue-collar employees, whose performance is more evident on the countable and measurable quantitative indexes. Forced ranking systems direct managers to evaluate their employees' performance against other employees, as well as against pre-determined standards. While the top 5-10 per cent of performers is amply rewarded, employees who fail in the lowest group are typically given 
counselling, improvement plans and so on, and cannot re-sign their labour contracts with the companies if they are in the bottom group two or three consecutive times.

\section{Insert Table 2 here}

Forced distribution promotes competition amongst colleagues, and thus can damage their harmonious relationships. Presumably, the transfer of the system into the Vietnamese subsidiaries could meet strong reactions and even refusal from the local employees. However, in practice, no particular constraint on the implementation of forced distributions was recorded in the present study. Several explanations exist for the high level of acceptance of the transferred leadership styles in the Vietnamese subsidiaries. As far as performance-oriented leadership style is concerned, the breakdown of the centrally planned economy (which led to the collapse of communist model of an egalitarian model of income distribution) has made capitalist countries' ways of distributing principles (which are strongly based on individual performance) more acceptable to the society in general, and employees in particular. Vietnamese employees have come to consider performance-related payment and performanceoriented leadership styles as important dimensions of modern management practices.

Vietnamese people avoid conflicts and tend to protect their social standing and maintain harmonious relationships. They favour compromise rather than open discussion of opposing views and avoid face-to-face disagreement (Quang, 2002). These characteristics may hinder the transfer of participative and performanceoriented leadership styles. However, ample evidence collected in this research indicates that the two leadership styles are successfully transferred to the Vietnamese subsidiaries smoothly without resistance from local employees. This may be explained by the fact that there are certain similarities between the principles of two 
leadership styles and some communist ideology. Both emphasise equality and empowerment. Prior to Doi Moi, SOEs were governed by the 'Four Committees', consisting of the Communist Party representative, the board of directors, the trade union representative, the youth union representative, and sometimes the women's association representative. Any decision had to be made with the combined consent and under the supervision of the Four Committees, after a process of collecting the 'democratic' voicing of employees' opinions (Vo, 2009). Although SOEs operated in a hierarchical order, the concept of 'grassroots empowerment' was explicitly expressed and exercised. However, participative leadership style, especially when undertaken with performance-oriented leadership, expected the individual to take personal responsibility, and performance was closely linked to rewards. In contrast, the exercise of collectivism and democracy in SOEs, coupled with a non-causal relationship between payment and performance, led to poor economic performance in the state sector.

Recent research suggests that Vietnamese employees can accept criticism and be motivated to discuss and resolve issues openly to develop genuine harmony (Vo, 2009). Although interviewed expatriates admitted that they sometimes felt the need to 'tone down' their criticism to their local employees, they reported having good and through discussions with Vietnamese employees, which also covered negative issues. This success may be explained by a combination of factors, including good relationships between managers and subordinates, tolerance for a 'foreigner' from the employee side, and a cultivated company culture of open discussion. It is thus argued that cultural problems are more a potential than a real difficulty, and that they are not overwhelming constraints to the implementation of Anglo leadership styles, and can be overridden by a strong company culture. 


\section{Adaptation to the local environment}

Oldham and Cummings (1996) found that employees produce the best outcomes when they work on complex, challenging tasks and are supervised in a non-controlling way. In practice, employees at different organisational levels diverge in their attitudes and subsequent reactions toward the same leadership practices. Interviewed managers agreed that participative leadership is more suitable for managerial staff members. Because their jobs are less routine and subject to more uncertainty, managers needed more autonomy and discretion to accomplish their tasks (Wall et al., 2002; Holden \& Roberts, 2004; Kanter, 2004). On the other hand, while enjoying the chance to voice their concerns, provide opinions and share feedback with their colleagues and supervisors, the majority of lower-level employees still relied on supervisors' direct instructions. A marketing manager of FMCG Co3 revealed:

The company's leadership style emphasises empowerment; thus I encourage and sometimes, demand participation in decision-making processes. However, some subordinates are unhappy with that. They argue that they cannot see a solution [for a problem] for themselves so they go to see me. They do not want to see me only to be asked what they think the solution should be!

The problem may lie with the education system. Even though mass education level is high, Vietnam still suffers from a significant scarcity of highly skilled labour.

Furthermore, investment and enrolment in vocational and technical education and training systems have been persistently low (Vo, 2009). Ill-equipped in terms of knowledge and skills, workers are more likely to exhibit high levels of dependence on their managers.

The nature of industry also has a strong influence on the reception of participative leadership. The automotive and energy industries, which require high level of skills and education from shopfloor workers, witness much stronger bottom-up 
empowerment and innovation; while the FMCG industries show a more laid-back attitude in employee participation at shopfloor level.

As suggested by institutional theorists, organisations may achieve legitimacy by becoming 'isomorphic' with the institutional environment (DiMaggio and Powell, 1991). MNCs might manage to achieve legitimacy in the host country by adaptation to secure local modification of centrally imposed policies. Evidence exists of US MNCs strengthening participative and performance-oriented leadership styles by simultaneously adopting 'humane' leadership styles. The humane style stresses compassion and generosity, patience, support and concerned for the wellbeing of others (House et al., 2007). In contrast to American culture, the boundary of work and personal life in Vietnam is blurry. Managers often develop personal relationship with their subordinates outside work. At work, they often demonstrate concern for employees' wellbeing in order to secure devotion and loyalty. The researchers observed that some older managers casually address themselves as 'dad' and their young subordinates as 'daughter' or 'son'. Management also makes sure that they are the main source of welfare and paternalistic generosity. They add a 'personal touch' to their management styles by visiting the sick, attending weddings and funerals of employees and their immediate family members, presenting gifts and greeting messages on birthdays, national holidays and so on.

\section{The reception of leadership styles of older and younger generations}

Differences in the attitudes, values and beliefs of each generation affect how different generations view leadership (Zemke et al., 2000; Conger, 2001; Meredith et al., 2002). A generation can be defined as: 
a cohort of persons passing through time passing through time who come to share a common habitus, hexis and culture, a function of which is to provide them with a collective memory that serves to integrate the generation over a finite period of time' (Eyerman and Turner, 1998: 93).

In this discussion, 'older generation' means those were born before the end of the Vietnamese-American War (1975) and ‘younger generation' as those born after that ${ }^{1}$.

The pre-1975 born generation lived through the centrally planned economy, and as such, they bear certain imprints and limitations of the old system. In most cases, they have been embedded the 'old' working environment that was built on strict hierarchical order. They expected long careers in one organisation and were loyal to their firms, thanks partly to their personal values, but also due to extremely limited job mobility, controlled by a government system of residence permits, which allowed persons to legally reside and work in one area only.

Older generations can be perceived as slow to change, less productive and less technologically savvy, which impedes their performance. Our interviews with managers revealed that when they could choose, companies preferred younger employees, who were unsullied by the working habits learned in Vietnamese firms. However, Vietnamese joint venture partners often sent some of their staff (both blue collar and white collar) to the new establishment at the start of operations (in the cases of Auto Co, FMCG Co1, FMCG Co2). There were two main problems relating to recruiting employees from the Vietnamese partners in the joint ventures: they often did not have the right skills (production and management alike) and they were deeply

\footnotetext{
${ }^{1}$ The younger generation is now in their early or mid-30s. They entered the workforce when foreign investment in the country expanded, with the large majority of MNCs establishing their subsidiaries in Vietnam in the mid or late 1990s. Those born in 1975 are also the very first batch of students, after the war, to study English in school instead of Russian. English is more than just a foreign language in Vietnam. Mastering the language opened the door for the youth to work in MNCs and be exposed to an influx of Western values, resulting in many changes in their values and attitudes.
} 
embedded in the social structure of SOEs. They were more likely to perceive local companies as referents and value them as ends in themselves (see for example, Bjorkman and Lu, 1997). In the experiences of the investigated companies, breaking with the legacy of the SOEs was reported as being more difficult than terminating the contracts of former SOE staff and recruiting new staff in their place.

However, in-depth interviews revealed that the issue is much more complex. First, interviewees expressed that there was a real need to recruit and retain older employees who have had rich experience in SOEs. For example, highly experienced painters are a 'rare commodity' in the automotive industry. Companies also hired middle-aged blue-collar workers in order to reduce the turnover rate (FMCG Co2, FMCG Co3) or take advantage of their valuable social and business networks and contacts (EN Co). While companies initially attempted to dismiss older employees, the current constant inflow of older employees to the organisations shows that by using proper selection methods, MNCs are confident with the quality of older employees. Many found the older generation in general to be very well adjusted to the new environment.

\footnotetext{
Many of them [older workers] are heads of quality control circles. Thanks to their rich experience, they not only are able to identify and solve product quality and production problems but also provide on-the-job training and lead their teams in these matters (interview with that HR manager,Auto Co).
}

Furthermore, many of the pre-1975 born managers consider their age as an advantage as Vietnamese employees have great respect for seniority.

Being older has certain advantages. They [subordinates] trust that I have experienced many things and overcome many difficulties during my working time. I am also respected for my old age. My judgements are seldom challenged because of all of these reasons. No one cares if my orders are direct or my communication is brief and abrupt and truth is, sometimes, rude. They might not tolerate that from a younger manager.

(Interview with a manager, EN Co)

The performance-oriented leadership style, which emphasises a high standard of work and personal achievement, was equally well received. One interviewed manager said: 
'In terms of achievement, there is no real difference between the two generations' (interview with a production manager at EN Co). Empirical evidence reveals that although a general perception exists that the older generation is resistant to change and clings to a traditional leadership style, in reality, the older generation have proven that they are resilient and very adaptive to the new environment and American leadership style. The breakdown of the centrally planned economy and the "new winds of a new era', as it is often mentioned in the Vietnamese media, demanded dramatic and swift changes in people's mindsets which, under normal circumstances would require a very long time to realise. In this case, a transitional society is a good context for the successful application of Anglo leadership styles.

The younger generation (those born after 1975) is the very first generation after the Vietnamese-American War to have studied English at school, entered the workforce and sought employment with MNCs after the Doi Moi policy was introduced. They were the first to be exposed to an influx of non-communist, Western values, resulting in many changes to their personal values and attitudes. This generation has experienced periods of economic distress — and recently, prosperity. They have witnessed radical social changes, instability and chaos, including the collapse of the communist system, the emergence of the market-oriented economy, the privatisation of the state sector and rapid technological change. The net effect has been the creation of emotional memories (Conger, 1998: 10), and therefore the younger generation have learned to be opportunistic, financially self-reliant and entrepreneurial risk takers.

While older generations can be recruited through different channels, including transfers from JVs and personal referrals, during the establishment period of the companies, post-1975 born employees, on the contrary, are only recruited after going through rigorous selection processes. With regard to the selection criteria, the studied 
companies use their global 'competence list'. Candidates for white collar positions are rated based on educational and training experience, past performance, leadership, commercial awareness, teamwork spirit, communication, competitive/entrepreneur spirit, motivation, adaptability, resourcefulness, interest in position, knowledge, behaviour, etc. Some concepts, such as motivation, resourcefulness, competitive spirit, are considered as 'Western concepts' that are quite unfamiliar to the Vietnamese. This is to say that the selected post-1975 born employees are those who are assessed as compatible with the company's Western cultures.

The younger generation display a consistently high need for autonomy, and seem to take a participative leadership style for granted, claiming it to be 'standard practice' (focus group at FMCG Co3), and 'the way it should be' (focus group at EN Co). They enjoy providing inputs in decision-making processes and yearn for delegation and autonomy. For example:

I really like my boss' management style. He often tells me to 'decide and take action - let me know what you did'. Although he has a 'hands-off' policy, he follows up with me to see the effectiveness of the delegated responsibility, which is necessary in my case as I am still quite junior. I appreciate his feedback, which is very helpful for coaching and development purposes.

(Interview with an employee, FMCG Co2)

They considered a performance-oriented style as 'necessary for the survival of firm' (interview with an employee at FMCG Co1). One interviewed manager in FMCG Co3 said:

I think a good leader should encourage inputs and gather everyone's opinions in the decisionmaking process while a good employee should be able to make decisions. I enjoy taking responsibility. As an associate manager I can sign off for any expenses up to five thousand dollars without waiting for my boss to see the paperwork and approve it - that gives me a sense of autonomy albeit within a boundary. 
This cohort is certainly not afraid of questioning their leaders' decisions. An example that illustrates this statement was provided by an interviewed manager of this generational cohort. In 2002 FMCG Co3 aimed to compete and expand their market share of sanitary products. The manager realised that their sanitary pads should have a higher level of absorption, smaller width and softer edges to reduce irritation for users. However, this innovation meant an increase of 15 per cent in production cost, changes in production process and purchase of new machinery. Even though initially she met strong resistance from both local and regional levels, her innovation was approved. The resulting increase in sales helped FMCG Co3 lead the feminine care product market in subsequent years.

A small proportion of the younger generation, who normally gained their education overseas in developed countries, such as the US, Europe and Singapore, advanced quickly on the corporate ladders and is considered as the 'elite' group. Many work at a middle or top management level in the examined MNCs. Embracing Western values, they do not differ much from their counterparts in Western countries. An expatriate manager of EN Co made a comment that some members of the new generation of managers in the Vietnamese subsidiary are very competitive and direct in their manner. This 'un-Asian' manner is an indication of the real transformation of Vietnamese organisational behaviours.

\section{Discussion and conclusion}

Despite a deeply rooted cultural heritage defined strongly by Confucius influences, the liberalisation of the Vietnamese economy through the introduction of Doi Moi has led to a transformation of business and cultural practices, and has added greater complexity to the business environment (Quang and Vuong, 2002). The findings from 
this study confirm that as a host for Western leadership styles, Vietnam exhibits the qualities of a nation undergoing significant transformation. While some of the underpinnings of the Vietnamese national and business culture (for example, high power distance, authoritarian, command-based leadership, collective interests over self-interest) may be seen as conflicting with the behaviours being cultivated through these two leadership approaches, the transfer process is supported at a macro level through the modernisation of the macro-economic environment and through the cultivation of an American business culture at the micro-firm level. Regarding the former, the effects of national culture are pervasive; the values that characterise organisations are likely to parallel the values of the national culture in which the organisation operates (Rhody and Tang 1995). The cultivation of an American-style of culture within the organisations may therefore be aided by the developments occurring in the broader socio-economic environment which render Western leadership styles more acceptable and even positive.

The reception of the participative and performance-oriented style was also partly influenced by certain congruencies with the ideologies of the former Communist regime, particularly those of equality and empowerment. The openness of the Vietnamese to these two leadership styles is hence not only a product of the contemporary social, political and economic developments, but is also borne of its historical underpinnings. While such similarities and consistencies aid the reception of leadership styles, this study highlights that differences should not be considered a hindrance. Alternatively, ideas about leadership are influenced by situations and organisational cultures (Lord, Brown, Harvey, \& Hall, 2001) and in some circumstances, an organisational culture can overpower the effects of national culture (Nakata and Sivakumar, 1996). Therefore, and as supported by this study, the creation 
of a strong corporate culture may effectively assist the organisation to surpass the developments occurring in the wider environment.

A key finding through our empirical research was the adoption of a humane approach to leadership as a means of facilitating the transfer of the participative and performance-oriented leadership styles to the Vietnamese context. In their research, Quang et al. (1998) identify ‘people orientation' as a leadership characteristic that is valued and utilised by both local Vietnamese and international managers. Bass (1997) suggests that mutual obligation between the leader and their followers in collectivistic cultures underlines the moral responsibility that leaders have to take care of their employees, and thus facilitates an individualised consideration of employees' interests. This study concurs with these findings, and also confirms the GLOBE study, where leadership traits were found to differ in terms of how they were expressed and enacted in different societies.

Specifically, greater blurring in the boundaries between work and home life within the Vietnamese culture is reflected in a higher level of involvement of leaders in the nonwork lives and activities of employees. Thus, greater acceptance of the Western approaches of participative and performance-oriented leadership was ascertained through the individual endorsement of these measures in a way that is essentially more closely aligned with the Vietnamese style of leading. These findings support the view of Hofstede (1983: 88): 'practice is usually wiser than theory'; organisational effectiveness in varying cultures are highly contingent on the capacity of leaders to adapt foreign leadership ideals to local conditions (Hofstede, 1983: 88). In the case studies, success was largely determined by the process of adaptation, which was facilitated through the amalgamation of Western principles of leadership with those Vietnamese styles recognised as also having consistency with the home countries' 
particular values sets. The integration of a humane approach, which essentially highlights the relational elements of leader-follower interactions, represents an integral means of reconciling or reducing the cultural gap.

The findings from this study also highlight the multiple layers of complexity that exist in considerations of the context of transfer. Importantly, these go beyond the notion of national culture, where the bulk of the existing literature has focused its inquiry (Egri and Ralston, 2004) and emphasises the importance of the subcultures that comprise it. Egri and Ralston (2004) highlight generation as one component of a national subculture; one that reflects the values of a particular period in history. In terms of Vietnam, Tang et al. (2007) warns against assuming that a homogeneous cultural value exists across the generations. They argue that the older generations in Vietnam endured a very different socio-economic and political context, one defined by significant chaos and instability, which led to the formation of a very different value set. 'On the other hand, the younger generations are strongly influenced by the education system, which promotes individualism, empowerment and innovation; and are hence more closely aligned with Western values. While the generation gap and the intergenerational values conflicts that define it may create further intricacies in the transfer of leadership styles, the findings from this study suggest reconciling differences may not be as difficult as first thought. Specifically, older generations were found to be surprisingly receptive to both leadership approaches, despite commonly held assumptions about their being less open to cultural change. This suggests some progress has been made within the society to shift towards a market economy, and in adapting to different styles of leadership (Quang, and Vuong, 2002). The truly transformational element of the business environment was reflected in the changing values found among the younger generations. Egri and Ralston (2004) 
highlight that generation subcultures represent an informative gauge of the evolution of culture change. Younger generations were found to be even more receptive of the participative and performance-oriented leadership styles than older generations, and were well placed within the wider transformations occurring. These changing values were not only apparent amongst younger generation employees, but also the new, younger breed of managers emerging from organisations in the Vietnamese context (Quang et al., 2002). The study by Egri and Ralston (2004) suggests that the value orientations of the future generations of US and Chinese executives will have many common characteristics, particularly in terms of their openness to change and tendency towards less conservative attitudes than previous generations. The next generation of Vietnamese leaders can therefore be expected to adopt many of the practices introduced by expatriate managers into the business environment. This reflects findings of Quang and Vuong (2002) regarding the increasing ‘importation' of Western styles of management into the Vietnamese context through expatriate leaders.

Where difficulties were experienced in the transfer of the two leadership styles, this was mostly the case within the blue-collar workforce, and was largely due to the limited education of the recipients. Vroom and Jago (2007) note that where quality decisions are expected to be made, the choice of leadership style is highly dependent on the knowledge of the leader and their followers. This study provides evidence of a participative style being more suited to a workforce that is highly skilled and educated. Differences in skills sets and educational levels are apparent not only in different industry contexts, but also across different levels of the hierarchy. Therefore, while a particular leadership style may be deemed appropriate for certain levels in the hierarchy due to higher levels of education and therefore more openness to change (for example, the participative style at the managerial level), their appropriateness 
may be reduced the closer you get to the shop floor. Situational determinants therefore play a defining role in the process of transfer; not only in terms of gauging the appropriateness of the leadership style to the particular circumstance, but also to the extent to which it will be received.

In summary, as noted by Muczyk et al. (2008), leadership is a dynamic process, and adaptation is an essential part of it. Within the context of a society undergoing significant transformation, the leader must be flexible and capable of moving — not only with the changes that are occurring at the macro-level socio-political and economic environment, but also the related movements in the value systems of the organisation's constituents. More importantly, the subcultures comprising the organisational and national culture must also be determined, because value sets are not universal (Tang et al., 2007). The success of the process also depends on contingencies which go beyond considerations of just the national culture. This calls for a certain type of dynamism on the part of the leader, particularly where societies are undergoing transition, and various levels of complexity define the leadership terrain. 


\section{References}

Adler, N.J. (1983). A typology of management studies involving culture. Journal of International Business Studies. Fall, pp. 29-47.

Ahearne, M., Mathieu, J. \& Rapp, A. (2005). To empower or not to empower your sales force? An empirical examination of the influence of leadership empowerment behavior on customer satisfaction and performance. Journal of Applied Psychology, 90, 945-955.

Arnold, J.A., Arad, S., Rhoades, J.A. \& Drasgow, F. (2000). The empowering leadership questionnaire: The construction and validation of a new scale for measuring leader behaviors. Journal of Organizational Behavior, 21, 249-269.

Ashkanasy, N.M. (2007). The Australian enigma. In Chhokar, J.S., Brodbeck, F.C. \& House, R.J. (eds), Culture and leadership across the world: The GLOBE Book of In-Depth Studies of 25 Societies, Lawrence Erlbaum Associates: Mahwah, NJ, pp. 299-333.

Avolio, B. (1994). The 'natural': Some antecedents to transformational leadership. International Journal of Public Administration, 17, 1559-1581.

Ayman, R. \& K. Korabik (2010). Leadership. Why Gender and Culture Matter. American Psychologist, 65(3), 13.

Bass, B. (1998). Two decades of research and development in transformational leadership. European Journal of Work and Organizational Psychology, 8, 9-32.

Bjorkman, I. \& Lu, Y. (1997). Human resource management practices in foreign invested enterprises in China: What has been learned? In Stewart, S. \& Carver, A. 
(eds) A coming of age: developments in Sino-Foreign joint ventures. Advances in Chinese Industrial Studies, vol. 5, London: JAI Press.

Brodbeck, F.C. (2000). Cultural variation of leadership prototypes across 22 European countries. Journal of Occupational and Organizational Psychology, 73, 1-29.

Chhokar, J.S. et al. (eds) (2007). Culture and Leadership across the World: The GLOBE Book of In-Depth Studies of 25 Societies, Mahwah, NJ: Lawrence Erlbaum.

Conger, J. (2001). How 'Gen X' manage. In Osland, J., Kolb, D. \& Rubin, I.W. (eds), Organizational Behavior Reader, Prentice-Hall, Upper Saddle River, NJ, pp. 919.

Davenport, T.H. \& Prusak, L. (1998). Working knowledge: how organisations manage what they know, Harvard Business School Press, Boston.

DiMaggio, P.J. \& Powell, W.W. (1991). The iron cage revisited: institutional isomorphism and collective rationality in organization fields. In Power, W.W \& DiMaggio, P.J. (eds) The new instutionalism in organizational analysis, Chicago and London: The University of Chicago Press, pp. 41-63.

Dorfman, P.W. \& House R.J. (2004). Cultural influences on organizational leadership. In House, R.J., Hanges, P.J., Javidan, M., Dorfman, P.W. \& Gupta, V. (eds), Culture leadership and organizations: The GLOBE study of 62 societies, London: Sage, pp. 51-73.

Dorfman, P.W., Hanges, P.J. \& Brodbeck, F.C. (2004). Leadership and cultural variation. In House, R.J., Hanges, P.J., Javidan, M., Dorfman, P.W. \& Gupta, V. 
(eds), Culture leadership and organizations: The GLOBE study of 62 societies, pp. 669-722, Sage, London.

Dowling, P. \& Welch, D. (2004). International human resource management: managing people in a global context, London: Thomson Learning.

Feldman, S.P. (1986). Management in context: an essay on the relevance of culture to the understanding of organizational change. Journal of Management Studies, 23(6), 587-607.

Gamble, J. (2001). Transferring business practices from the United Kingdom to China: the limits and potential for convergence, paper presented to 'Multinational companies and human resource management: Between globalisation and national business systems' conference, De Montfort University Graduate School of Business, Leicester.

Gerstner, Charlotte. R. \& Day, D.V. (1994). Cross-cultural comparison of leadership prototypes. Leadership Quarterly, 5(2), 121-134.

Hirst, P. \& Thompson, G. (1999). Globalization in question, 2nd edition, Polity Press, Cambridge: England.

Hofstede, G. (1976). Nationality and espoused values of managers. Journal of Applied Psychology, 2, 148-155.

Hofstede, G. (1980). Motivation, leadership, and organization: Do American theories apply abroad? Organizational Dynamics, 9, 42-63.

Hofstede, G. (1997). Cultures and organizations: software of the mind, 2nd edition, London: McGraw-Hill. 
Hofstede, G. (1980). Culture's consequences: International differences in work related values. Newbury Park: Sage Publications.

Hofstede, G. (2006). What did GLOBE really measure? Researchers' minds versus respondents' minds, Journal of International Business Studies, 37(6), 882-896.

Holden, L. \& Roberts, I. (2004). The depowerment of European middle managers: Challenges and uncertainties. Journal of Managerial Psychology, 19, 269-287.

House, R.J. et al. (eds) (2007). Culture, Leadership, and Organizations: The GLOBE Study of 62 Societies. Thousand Oaks, CA: Sage.

House, R.J., Hanges, P.J., Ruiz-Quintanilla, S.A., Dorfman, P.W., Javidan, M., Dickson, M.W., Gupta, V. \& GLOBE Associates (1999). Cultural influences on leadership and organizations: Project GLOBE. In Mobley, W.H. Gessner, M.J. \& Arnold, V. (eds) Advances in Global Leadership, vol. 1, JAI Press, Stamford, CT, pp. 171-233.

Jung, D.I. \& Avolio, B.J. (1999). Effects of leadership style and followers' cultural orientation on performance in group and individual task conditions. Academy of Management Review, 42(2), 208-28.

Kanter, R.M. (2004). The middle manager as innovator. Harvard Business Review, July-August, 150-160.

Khandwalla, P. (1995). Management Styles, New Delhi: Tata McGraw-Hill Publishing Co. Ltd. 
Leach, D., Wall, T.D. \& Jackson, P.R. (2003). The effect of empowerment on job knowledge: An empirical test involving operators of complex technology. Journal of Occupational \& Organizational Psychology, 76, 27-53.

Meredith, G., Schewe, C.D. \& Hiam, A. (2002). Managing by Defining Moments, Hungry Minds, New York, NY.

Offermann, Lynn. R. \& Hellmann, P.S. (1997). Culture's consequences for leadership behavior: National values in action. Journal of Cross-Cultural Psychology, 28(3), $342-351$.

Oldham, G.R., \& Cummings, A. (1996). Employee Creativity: Personal and Contextual Factors at Work. Academy of Management Journal, 39(3), 607-34.

Quang, T. \& Vuong, N.T. (2002). Management Styles and Organisational Effectiveness in Vietnam. Research and Practice in Human Resource Management, 10(2), 36-55.

Quang, T. (1997). Conflict Management in Joint-Ventures in Vietnam, Transitions, $38(1 \& 2), 282-306$.

Ralston, D.A., Nguyen, V.T. \& Napier, N.K. (1999). A Comparative Study of the Work Values of North and South Vietnamese Managers, Journal of International Business Studies, 30(4), 655-672.

Roberts, K.H. \& Boyacigiller, N.A. (1984). Cross national organizational research: the grasp of the blind men. Research in Organizational Behavior, vol. 6, JAI Press: Greenwich, CT. 
Sashkin, M. (2004). Transformational leadership approaches. In Antonakis, J., Ciancolo, A. \& Sternberg, R. (eds), The nature of leadership, Thousand Oaks, CA: Sage, pp. 171-196.

Tran, V.H. (ed.) (1997). Economic development and prospects in the ASEAN: foreign investment and growth in Vietnam, Thailand, Indonesia, and Malaysia, Basingstoke: Macmillan.

Tsui, A.S., Schoonhoven, C.B., Meyer, M.W., Lau, C.M. \& Milkovich, G.T. (2004). Organization and management in the midst of societal transformation: The People's Republic of China. Organization Science, 15, 133-144.

Vo, A.N. (2009). The Transformation of Human Resource Management and Labour Relations in Vietnam, Oxford: Chandos Publishing.

Vroom, V.H. \& Jago, A.G. (1988). The new leadership: Managing participation in organizations, Englewood Cliffs, NJ: Prentice-Hall.

Vroom, V.H. \& Jago, A.G. (2007). The role of the situation in leadership. American Psychologist, 62, 17-24.

Wall, T.D., Cordery, J.L. \& Clegg, C.W. (2002). Empowerment, performance, and operational uncertainty: A theoretical integration. Applied Psychology: An International Review, 51, 146-169.

Xinzhong, Y. (2000). An Introduction to Confucianism, Cambridge: Cambridge University Press.

Xu Huang \& Kan Shi \& Zhijie Zhang \& Yat Lee Cheung (2006). The impact of participative leadership behaviour on psychological empowerment and 
organizational commitment in Chinese state-owned enterprises: the moderating role of organizational tenure. Asia Pacific Journal of Management, 23, 345-367

Yin, R.K. (2003). Applications of case study research, 2nd edition, London: Sage.

Zemke, R., Raines, C. \& Filipczak, B. (2000). Generations at Work: Managing the Clash of Veterans. Boomers, Xers, and Nexters in Your Workplace, New York, NY: AMACOM. 
Table 1 Interview distribution

\begin{tabular}{|l|c|c|c|c|c|}
\hline & \multicolumn{2}{|c|}{ One to one interview } & \multicolumn{3}{c|}{ Focus group } \\
\hline & Managers & Employees & $\begin{array}{l}\text { Pre-1975 born } \\
\text { employees }\end{array}$ & $\begin{array}{l}\text { Post-1975 born } \\
\text { employees }\end{array}$ & Mixed group \\
\hline Auto Co & 4 & 5 & & 1 & 1 \\
\hline FMCG Co1 & 5 & 6 & 1 & 1 & 1 \\
\hline FMCG Co2 & 7 & 9 & 1 & 1 & 1 \\
\hline FMCG Co3 & 3 & 5 & & & 1 \\
\hline EN Co & 6 & 7 & & & 1 \\
\hline Total & & 57 & & & \\
\hline
\end{tabular}

Table 2 Forced distribution system applications in the studied companies

\begin{tabular}{|l|l|l|}
\hline Company & White-collar employees & Blue-collar employees \\
\hline Auto Co & $\begin{array}{l}\text { A (5-10\%), B+, B, C. 'Looser' forced distributions are applied for } \\
\text { blue-collar workers. }\end{array}$ \\
\hline FMCG Co1 & $1(15-20 \%), 2(65-70 \%), 3(15 \%)$. \\
\hline FMCG Co2 & $\begin{array}{l}\text { Exceptional (15\%), meet } \\
\text { expectation, below expectation } \\
(5 \%)\end{array}$ & $\begin{array}{l}\text { Ratings are the same as white-collar } \\
\text { group. However, forced distribution } \\
\text { is not applied. }\end{array}$ \\
\hline FMCG Co3 & $\begin{array}{l}\text { Exceed expectation (4-5\%), Meet } \\
\text { expectation, Does not meet } \\
\text { expectation (1-2\%), Not rated } \\
\text { for temporary workers). }\end{array}$ & $\begin{array}{l}\text { Ratings are the same as white-collar } \\
\text { group. However, forced distribution } \\
\text { is not applied. }\end{array}$ \\
\hline EN Co & $\begin{array}{l}\text { Exceed expectation (15 - 20\%), meet expectation (65-70\%), below } \\
\text { expectation (15\%). }\end{array}$ \\
\hline
\end{tabular}

